\title{
The Comparison of Psychological Characteristics between Korean and Japanese Women Pro-Basketball Players
}

\author{
Eun Joo Ha1 ${ }^{1}$, Kyoung Doo Kang ${ }^{2}$, and Doug Hyun $\mathrm{Han}^{2 凶}$ \\ ${ }^{1}$ Wake Up Body Center, Suwon, Republic of Korea \\ ${ }^{2}$ Department of Psychiatry, Chung Ang University Hospital, Seoul, Republic of Korea
}

Objective Korea (ranked 16th) and Japan (ranked 13th) show similar rankings, skills, and performance in basketball. However, the countries differ in size and the number of players in the national women's basketball system. The current study aimed to compare the psychological factors (anxiety, and temperament and character) and the national teams' players' characteristics between 80 Korean (WKBL players) and 76 Japanese (WJBL players) female basketball players in six professional teams each.

Methods All players were asked to complete demographic characteristics including age, career years, position, number of past and presents positions, and clinical scales, including sports anxiety, state anxiety, trait anxiety, and the Temperament and Character Inventory (TCI). Hierarchical logistic regression analyses among individual factors, physical factors, basketball status, anxiety factors, and temperamental conditions were conducted.

Results In all basketball players, all five models were significantly associated with national team players. The TCI factors were the strongest predictive factors for Korean national team players, while the anxiety factors were the strongest predictive factors for Japanese national team players. WKBL players in all positions showed higher sports anxiety and harm avoidance than WJBL players. WJBL players scored higher on self-directedness and cooperativeness than WKBL players.

Conclusion For predicting national team players, temperament and character were crucial factors in WKBL players where anxiety was the most important one for WJBL players.

Psychiatry Investig 2019;16(7):524-531

Key Words Basketball, Temperament character inventory 240, Anxiety, Korean, Japan.

\section{INTRODUCTION}

In the world's women basketball ranking 2017, Australia, China, Japan, and Korea were the top four Asian-Pacific countries. ${ }^{1}$ Of these four countries, Korea (ranked 16th) and Japan (ranked 13th) showed similar rankings, skills, and performance. ${ }^{1}$ However, there were differences between the two countries in terms of size and number of players. In 2016, the Korean basketball association (KBA) reported that there were 161 women basketball players in 20 high schools, 94 women basketball players in nine colleges, and 92 women pro-basketball players in six pro teams, 1 while the Japan basketball

\footnotetext{
Received: August 15, 2018 Revised: April 18, 2019

Accepted: April 25, 2019

$\triangle$ Correspondence: Doug Hyun Han, MD, PhD

Department of Psychiatry, Chung Ang University Hospital, 102 Heusoek-ro, Dongjak-gu, Seoul 06973, Republic of Korea

Tel: +82-2-6299-3132, Fax: +82-2-6299-1114, E-mail: hduk70@gmail.com

(c) This is an Open Access article distributed under the terms of the Creative Commons Attribution Non-Commercial License (https://creativecommons.org/licenses/by$\mathrm{nc} / 4.0$ ) which permits unrestricted non-commercial use, distribution, and reproduction in any medium, provided the original work is properly cited.
}

association (JBA) reported that there were 60,138 women basketball players in 3,741 high schools, 5,282 women basketball players in 330 colleges, and 178 women pro-basketball players in 12 pro teams. ${ }^{2}$ In view of the limitations in system supports, we were curious about the factors that would compensate for those limitations.

The age and career of track and field athletes were associated with improvement of performance in long and high jump. ${ }^{3}$ In national basketball association (NBA) players, anthropometrics including height without shoes, standing reach, weight, wingspan, and hand length were predictive variables of future performance, including athletic abilities and basketball skills. ${ }^{4}$ In addition, the anthropometric profiles of basketball players have been important factors in the selection process. ${ }^{5}$ Moreover, players' position on the court is highly determined by their height and weight. ${ }^{6}$

Anxiety is also a very important psychological factor for sports performance. ${ }^{7-9}$ Competitive anxiety in sports was associated with performance and stress was associated with increased salivary steroid response. ${ }^{9}$ The competitive trait anxi- 
ety in sports is negatively associated with performance in power lifting. ${ }^{7}$ State anxiety is thought to be associated with performance with self-focus and perceived control under pressure in athletes. ${ }^{8}$ The trait anxiety of professional baseball players in the starter group was higher than that in the nonstarter group. ${ }^{10}$ In addition, both trait and state anxiety scores of the "winner" group were lower than those of the nonstarter group. ${ }^{11}$

In the assessment of sports teams and players, personalities, and characters were thought to be important factors for determining players' performance and goals. ${ }^{12}$ In very old personality studies, personality traits were associated with genetic and epigenetic influences on predictable behaviors of a person in response to outer stimuli. ${ }^{13,14}$ In sports players, personality traits have been associated with long-term success, performance, and starting position., ${ }^{5,10,15}$ The Temperament and Character Inventory (TCI) developed by Cloninger ${ }^{16}$ has been used to evaluate the temperamental traits of novelty seeking (NS), harm avoidance (HA), reward dependence (RD), and persistence as well as the characters of self-directedness (SD), cooperativeness, and self-transference (ST). In particular, the temperament dimension is controlled by a biological system including neurotransmitters of dopamine for NS, serotonin for $\mathrm{HA}$, and $\mathrm{RD}$ for noradrenergic activity. ${ }^{17}$ Generally, the risk-taking and exploratory features of NS are often highlighted. ${ }^{18}$ On the other hand, HA is associated with behavioral inhibition, cautiousness, and apprehensiveness. RD explained continuing behaviors that have been previously associated with reinforcement and maintained with others' approval. Lastly, persistence involves a heritable bias toward continuing and persevering without rewards. ${ }^{19}$ In addition, SD is thought to be associated with autonomy and life purpose; cooperativeness is associated with positive relationship with others; and ST is associated with personal growth and selfactualization. ${ }^{20}$ In our previous study of TCI with professional baseball players, the starter players showed higher NS scores than did the non-starter players. In addition, the players in the success group showed increased $\mathrm{RD}$ scores compared to those in the non-success group. ${ }^{10}$

Based on previous reports, we assumed that there were differences in basketball cultures between WKBL and WJBL league. The aim of the current study was to compare five factors, including individual factors, physical factors, basketball stats, psychological factors, and temperament and characteristics, between WKBL and WJBL players. In addition, we compared the competence of the players of both national teams in terms of five factors, using hierarchical logistic regression analysis.

\section{METHODS}

\section{Participants}

Eighty professional players in six professional teams of the WKBL and 76 professional players in six professional teams of the WJBL were recruited. All players were asked to complete demographic characteristics, including age, career years, position, number of past and presents positions, and clinical scales including sports anxiety, state anxiety, trait anxiety, and the TCI. The protocol of this study was approved by the OO University Institutional Review Board (IRB No. 10-065-10-18). Also, written informed consent was provided by all the participating players.

\section{Psychological Assessment Scales}

\section{State and trait anxiety inventory}

The Korean version of the state and trait anxiety inventory (STAI) form Y (STAI-KY) with 40 questions (20 for state anxiety and 20 for trait anxiety), as well as the Japanese version, STAI-JY, was used to assess the state and trait anxiety levels in Korean and Japanese players, respectively. ${ }^{21,22}$

\section{Sports anxiety scale}

The Korean version of the sports anxiety scale (SAS) form $\mathrm{K}$ (SAS-K) with 21 items (nine for somatic anxiety, seven for worry anxiety, and five for concentration) was used to assess the sports anxiety levels in Korean players. On a four-point Likert-type intensity rating scale ( $1=$ not at all; $4=$ very much so), respondents indicated the degree to which they generally experienced the 21 anxiety-related symptoms before and during the competition. Korean SAS had Cronbach's alpha values ranging from 0.80 to $0.88 .^{23}$ On the other hand, the WJBL were assessed using a questionnaire translated to Japanese because no previous studies used the SAS in Japanese.

\section{Temperament and character inventory}

For Korean players, the Korean version of the TCI was used to evaluate four dimensions of temperament and three dimensions of character. Korean TCI with Cronbach's alpha values from 0.60 to 0.85 consisted of 240 -items of true/false questions. ${ }^{24}$ For Japanese players, the Japanese version of the TCI was used. The Japanese TCI also had higher Cronbach's alpha values from 0.60 to $0.83 .^{25}$

\section{Data analysis}

First, individual factors, anthropometric, and psychological factors between Korean and Japanese basketball players were compared using independent $t$ test. Second, in multiple logistic regression analysis in all basketball players, a discrete 
set of hierarchical variables were added. The dependent variable of logistic regression analysis, "national team player," was operationalized as a binary code (1/0). The definition of a national team player was "a player selected as national team player at any period of high school, university, or professional league." In model 1, individual factors, including the chronological age and career years of basketball players, were recorded. In model 2, physical factors, including height $(\mathrm{cm})$ and weight $(\mathrm{kg})$, were recorded. In model 3 , basketball status, including position, number of past positions experienced and number of present playing positions, were recorded. In model 4, anxiety factors, including sports anxiety, state anxiety, and trait anxiety, were recoded. In model 5 , temperament and characteristic factors, including scores of NS, HA, RD, persistence, SD, cooperativeness, and ST, were recorded. Third, the differences in psychological factors between positions (guard, forward, and center) in each nation were analyzed with an ANOVA and a post-hoc test. Finally, the differences in psychological factors between Korean and Japanese guard players (Korean forward versus Japan forward, Korean center versus Japan center) were analyzed with an independent $t$ test and a Mann-Whitney U test.

\section{RESULTS}

\section{Comparison of five categorical factors between WKBL and WJBL players}

There were no significant differences in individual factors, physical factors, and basketball status between WKBL and WJBL players. However, WKBL players showed higher scores in sports anxiety, trait anxiety, and HA than WJBL players. In addition, WJBL players showed higher scores in SD and cooperativeness than WKBL players (Table 1).

\section{Comparison of anxiety and TCI between positions}

There were no significant differences in anxiety scores including spots anxiety, state anxiety, and trait anxiety in all women basketball players, the WKBL group, and the WJBL group (Table 2).

Among WKBL players, those in the center position showed

Table 1. Comparison of five categorical factors between Korean and Japanese women basketball players

\begin{tabular}{|c|c|c|c|}
\hline & Korean $(\mathrm{N}=80)$ & Japanese $(\mathrm{N}=76)$ & Statistics \\
\hline Age (years) & $24.7 \pm 4.2$ & $24.1 \pm 3.4$ & $\mathrm{t}=1.01, \mathrm{p}=0.31$ \\
\hline Career (years) & $13.5 \pm 4.3$ & $14.8 \pm 3.7$ & $\mathrm{t}=2.04, \mathrm{p}=0.04$ \\
\hline Height (cm) & $175.3 \pm 6.1$ & $174.7 \pm 7.8$ & $\mathrm{t}=0.53, \mathrm{p}=0.60$ \\
\hline Weight $(\mathrm{kg})$ & $66.3 \pm 8.1$ & $65.7 \pm 9.3$ & $\mathrm{t}=0.44, \mathrm{p}=0.66$ \\
\hline \multicolumn{4}{|l|}{ Position (N) } \\
\hline PG & 20 & 17 & \\
\hline SG & 14 & 12 & \\
\hline SF & 19 & 12 & $\chi^{2}=3.39, p=0.21$ \\
\hline $\mathrm{PF}$ & 14 & 15 & \\
\hline $\mathrm{Ct}$ & 13 & 20 & \\
\hline No. of past positions & $2.25 \pm 1.1$ & $2.28 \pm 1.1$ & $\mathrm{t}=0.15, \mathrm{p}=0.88$ \\
\hline No. of present positions & $1.38 \pm 0.49$ & $1.28 \pm 0.53$ & $\mathrm{t}=1.21, \mathrm{p}=0.09$ \\
\hline National player $(\mathrm{y} / \mathrm{N})$ & $18 / 62$ & $27 / 49$ & $\chi^{2}=3.22, p=0.08$ \\
\hline Sports anxiety* & $46.2 \pm 11.6$ & $34.8 \pm 9.3$ & $\mathrm{t}=6.72, \mathrm{p}<0.001$ \\
\hline State anxiety & $42.2 \pm 6.5$ & $40.5 \pm 6.9$ & $\mathrm{t}=1.65, \mathrm{p}=0.11$ \\
\hline Trait anxiety* & $47.0 \pm 7.0$ & $42.9 \pm 6.7$ & $\mathrm{t}=3.75, \mathrm{p}<0.001$ \\
\hline NS & $19.4 \pm 4.9$ & $20.7 \pm 5.1$ & $\mathrm{t}=1.62, \mathrm{p}=0.11$ \\
\hline $\mathrm{HA}^{*}$ & $20.4 \pm 5.6$ & $18.2 \pm 5.7$ & $\mathrm{t}=2.46, \mathrm{p}=0.02$ \\
\hline $\mathrm{RD}$ & $15.3 \pm 3.5$ & $14.6 \pm 3.0$ & $\mathrm{t}=1.26, \mathrm{p}=0.21$ \\
\hline $\mathrm{P}$ & $4.4 \pm 2.0$ & $4.6 \pm 1.8$ & $\mathrm{t}=0.84, \mathrm{p}=0.40$ \\
\hline $\mathrm{SD}^{*}$ & $23.3 \pm 5.8$ & $29.1 \pm 5.7$ & $\mathrm{t}=6.37, \mathrm{p}<0.001$ \\
\hline $\mathrm{C}^{*}$ & $27.4 \pm 6.1$ & $30.6 \pm 4.9$ & $\mathrm{t}=3.62, \mathrm{p}<0.001$ \\
\hline ST & $12.2 \pm 4.8$ & $12.8 \pm 5.4$ & $\mathrm{t}=0.77, \mathrm{p}=0.44$ \\
\hline
\end{tabular}

*statistically significant. PG: point guard, SG: shooting guard, SF: small forward, PF: power forward, Ct: center, NS: novelty seeking, HA: harm avoidance, $\mathrm{RD}$ : reward dependence, P: persistence, SD: self directedness, C: cooperativeness, ST: self transference 
lower persistence and SD scores than those in the guard and forward positions. In addition, players with guard position showed higher cooperativeness scores than those in the forward and center position (Table 2). Among WJBL players, there were no significant differences in anxiety and TCI scores between positions.

WKBL players in the guard position showed higher sports anxiety scores than WJBL players in the guard position. WKBL players in the forward position showed higher sports anxiety and trait anxiety scores than WJBL players in the forward position. WKBL players in the center position showed higher sports anxiety scores than WJBL players in the center position (Figure 1).

WJBL players in the guard position showed higher SD scores than WKBL players with guard position. WJBL players in the forward position showed higher SD and cooperativeness scores than WKBL players in the forward position. WJBL players in the center position showed higher persistence and SD scores than WKBL players in the center position (Figure 1).

\section{Hierarchical model for national basketball players}

Among all basketball players, all five models (individual factors, physical factors, basketball status, anxiety factors, and TCI factors) were significantly associated with national team players. With the highest step of chi-square value and improvement in classification accuracy, individual factors (age and career) were the strongest predictive factors of national team players. According to the Wald statistics for all independent variables, the variables of career, position, and $\mathrm{RD}$ were significant predictors of national team players (Table 3 ).

Regarding WKBL players, all five models were also significantly associated with national team players. With the high- est step of chi-square value and improvement in classification accuracy, TCI factors were the strongest predictive factors for national team players. According to the Wald statistics for all independent variables, the variables of number of past positions, sports anxiety, and NS were significant predictors of Korean national team players (Table 3 ).

Regarding WJBL players, all five models were also significantly associated with national team players. With the highest step of chi-square value and improvement in classification accuracy, anxiety factors were the strongest predictive factors for national team players. According to the Wald statistics for all independent variables, the variables of career, weight, sports anxiety, present position, and persistence were significant predictors of Japanese national team players (Table 3 ).

\section{DISCUSSION}

\section{Comparison of five categorical factors between WKBL and WJBL players}

WKBL players in all positions showed higher sports anxiety and HA than the WJBL players. HA was known to be closely associated with anxiety. ${ }^{20,26}$ It may be associated with the scale and size of the basketball support system. WJBL players with more opportunities to play in a larger system might have more frequently experienced competition than WKBL players. Mellalieu et al. ${ }^{27}$ suggested that more experienced players would possess greater self-confidence by controlling anxiety. However, high anxiety in sports was regarded as a signal for poor performance. Halvari and Gjesme ${ }^{28}$ suggested that trait anxiety was related to both pre-state anxiety and performance errors. High levels of anxiety produces more errors involving brain activity relative to both phobic and non-

Table 2. Comparison of anxiety and TCI between Korean and Japanese players

\begin{tabular}{|c|c|c|c|c|c|c|c|c|c|}
\hline & \multicolumn{3}{|c|}{ All women basketball players } & \multicolumn{3}{|c|}{ Korean women basketball players } & \multicolumn{3}{|c|}{ Japanese women basketball players } \\
\hline & Guard & Forward & Center & Guard & Forward & Center & Guard & Forward & Center \\
\hline $\mathrm{Sp}$ & $39.2 \pm 11.7$ & $41.0 \pm 12.8$ & $42.6 \pm 10.9$ & $43.6 \pm 12.6$ & $47.5 \pm 10.7$ & $49.5 \pm 10.6$ & $34.1 \pm 8.2$ & $33.1 \pm 10.5$ & $38.1 \pm 8.7$ \\
\hline St & $40.8 \pm 6.9$ & $42.4 \pm 5.6$ & $40.8 \pm 7.9$ & $42.1 \pm 7.4$ & $43.4 \pm 5.3$ & $39.5 \pm 6.3$ & $39.2 \pm 6.2$ & $41.1 \pm 5.7$ & $41.7 \pm 8.9$ \\
\hline $\operatorname{Tr}$ & $44.9 \pm 8.1$ & $45.6 \pm 6.7$ & $44.3 \pm 6.3$ & $46.5 \pm 7.8$ & $48.2 \pm 6.2$ & $45.4 \pm 6.8$ & $42.9 \pm 8.1$ & $42.3 \pm 5.8$ & $43.6 \pm 6.1$ \\
\hline NS & $19.5 \pm 5.1$ & $20.7 \pm 4.9$ & $19.9 \pm 4.9$ & $18.6 \pm 5.1$ & $20.0 \pm 5.1$ & $19.8 \pm 4.2$ & $20.6 \pm 5.1$ & $21.4 \pm 4.7$ & $19.9 \pm 5.5$ \\
\hline $\mathrm{HA}$ & $19.3 \pm 5.4$ & $19.1 \pm 5.7$ & $20.2 \pm 6.6$ & $19.5 \pm 5.0$ & $20.3 \pm 5.3$ & $23.2 \pm 7.3$ & $18.9 \pm 5.9$ & $17.6 \pm 5.9$ & $17.9 \pm 5.4$ \\
\hline $\mathrm{RD}$ & $15.6 \pm 2.8$ & $14.7 \pm 3.2$ & $14.2 \pm 3.9$ & $16.0 \pm 3.0$ & $15.2 \pm 3.3$ & $13.6 \pm 4.6$ & $15.0 \pm 2.5$ & $14.1 \pm 3.2$ & $14.6 \pm 3.0$ \\
\hline $\mathrm{P}$ & $4.8 \pm 2.1$ & $4.6 \pm 1.7$ & $3.8 \pm 1.8$ & $4.8 \pm 2.1^{* 1}$ & $4.6 \pm 2.0$ & $2.8 \pm 1.3$ & $4.8 \pm 2.1$ & $4.6 \pm 1.5$ & $4.6 \pm 1.8$ \\
\hline $\mathrm{SD}$ & $27.1 \pm 6.1$ & $26.0 \pm 6.6$ & $24.4 \pm 6.5$ & $24.7 \pm 5.5^{* 2}$ & $23.6 \pm 5.7$ & $18.9 \pm 4.6$ & $30.0 \pm 5.4$ & $29.0 \pm 6.6$ & $29.1 \pm 5.6$ \\
\hline $\mathrm{C}$ & $30.1 \pm 5.4$ & $28.0 \pm 6.3$ & $28.5 \pm 5.0$ & $29.7 \pm 5.8^{* 3}$ & $25.4 \pm 6.3$ & $26.3 \pm 4.7$ & $30.6 \pm 4.9$ & $31.2 \pm 4.8$ & $30.6 \pm 4.8$ \\
\hline ST & $11.9 \pm 4.5$ & $12.7 \pm 5.3$ & $12.9 \pm 5.9$ & $12.5 \pm 4.9$ & $12.4 \pm 5.0$ & $10.7 \pm 4.2$ & $11.3 \pm 3.9$ & $13.1 \pm 5.6$ & $12.8 \pm 5.4$ \\
\hline
\end{tabular}

Post hoc, ${ }^{*} 1$ : Guard=Forward $>$ Center, ${ }^{*} 2$ : Guard=Forward $>$ Center, ${ }^{*} 3$ : Guard $>$ Forward=Center in Korean women basketball, Sp: sports anxiety, St: state anxiety, Tr: trait anxiety, NS: novelty seeking, HA: harm avoidance, RD: reward dependence, P: persistence, SD: self directedness, C: cooperativeness, ST: self transference 

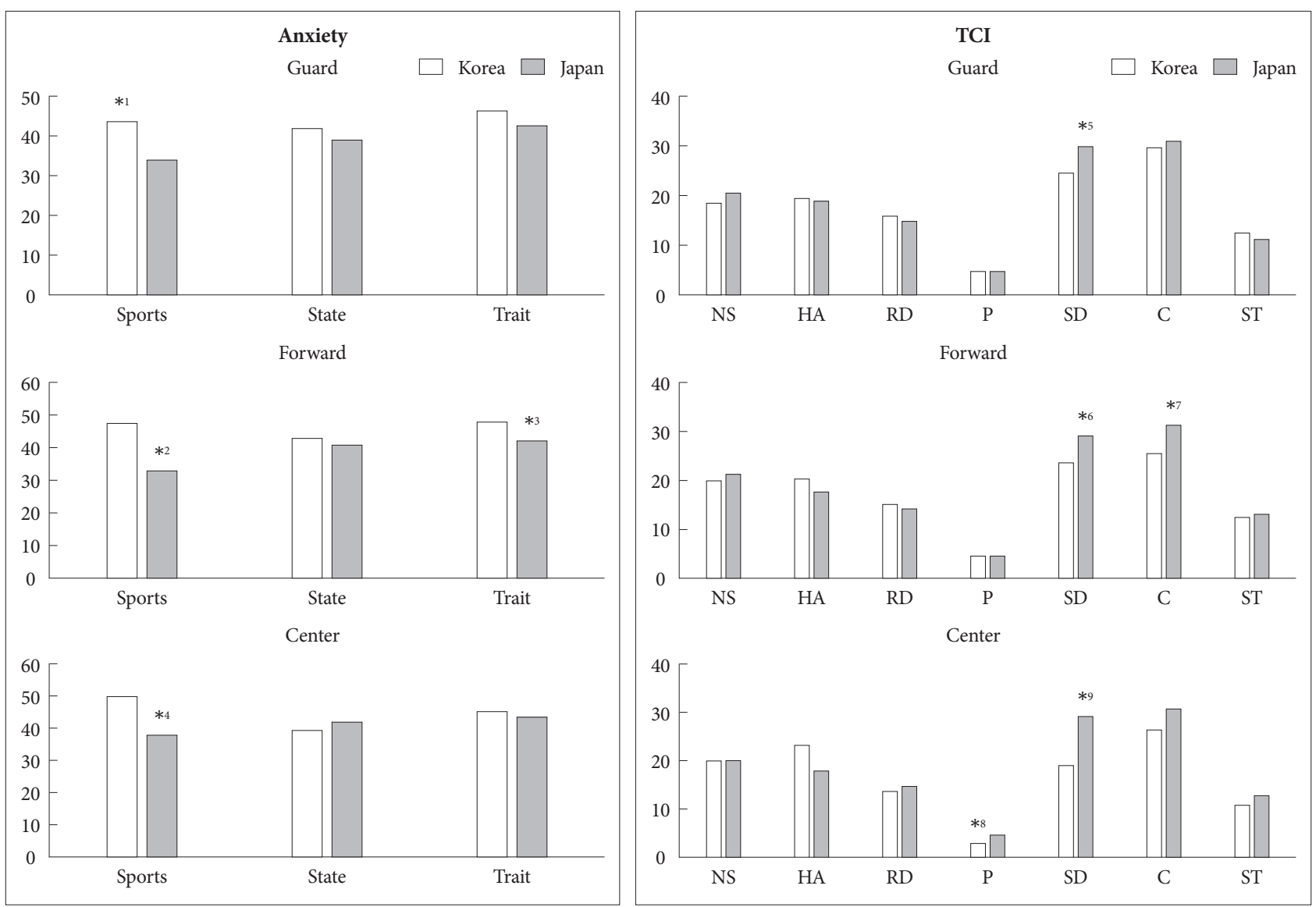

Figure 1. Comparison of $\mathrm{TCl}$ between Korean and Japan players. Independent $t$ test, ${ }^{*} 1: t=3.49, p=0.001,{ }^{*} 2: t=5.21, p<0.001,{ }^{*} 3: t=3.73$, $p<0.001,{ }^{*} 4: z=-2.84, p=0.004,{ }^{*} 5: t=-3.84, p<0.001,{ }^{*} 6: t=-3.45, p=0.001,{ }^{*} 7: t=-3.932, p<0.001,{ }^{*} 8: z=-3.95, p<0.001,{ }^{*} 9: z=-3.38$, $p=0.002$. NS: novelty seeking, HA: harm avoidance, RD: reward dependence, P: persistence, SD: self directedness, C: cooperativeness, ST: self transference, TCl: temperament and character inventory.

anxious control participants. ${ }^{29}$ In the case of basketball competition, high levels of anxiety would directly affect performance such as turnover and shooting success rates. ${ }^{30}$ According to International Basketball Federation (FIBA) records of the Women's Asia cup, the WKBL team had lower rates of shooting, turnover, and free-throw success rates than the WJBL. ${ }^{31}$ Among WKBL players, those in the center position had lower SD scores, and WKBL players in the guard position had higher cooperativeness scores than WKBL players in other positions. With these results, we cautiously suggest that Korean basketball may emphasize guard-oriented and outsidefocused (rather than inside-focused) strategies.

WJBL players had higher SD and cooperativeness scores than WKBL players in the current study. Moreover, the SD scores of WJBL players in all positions were higher than those observed in WKBL players in all positions. SD is characterized by responsibility and resourcefulness in initiating and organizing steps to achieve personal goals. ${ }^{20}$ In addition, SD is linked with autonomy. ${ }^{32}$ There were several reports representing positive effects of cooperativeness on basketball teams. ${ }^{33-35}$ The co- operative athletes were faster in achieving performance in response to stimulation, resulting in the use of cooperative rather than competitive motor strategies. ${ }^{33}$ In the analysis of ball possessions between the winning and losing basketball teams, the winning teams showed shorter ball possessions and more passes and more participating players than the losing teams. ${ }^{35}$ In the analysis of NBA 2008-2009 season data, Willer et al. ${ }^{34}$ suggested a direct reciprocal effect in which players who received assistance and got to score subsequently reciprocated their benefactors. Recently, WJBL won a championship in the 2017 FIBA Women's Asian Cup by defeating Korea, China, and Australia. We cautiously suggest that psychological characteristics could be related to the improvement of performance in Japanese women's basketball.

\section{Prediction of national basketball players in Korean and Japanese women basketball players}

Of the five models, temperament and characteristics were crucial factors for predicting national team players in WKBL players, while anxiety was the most important factor in WJBL 


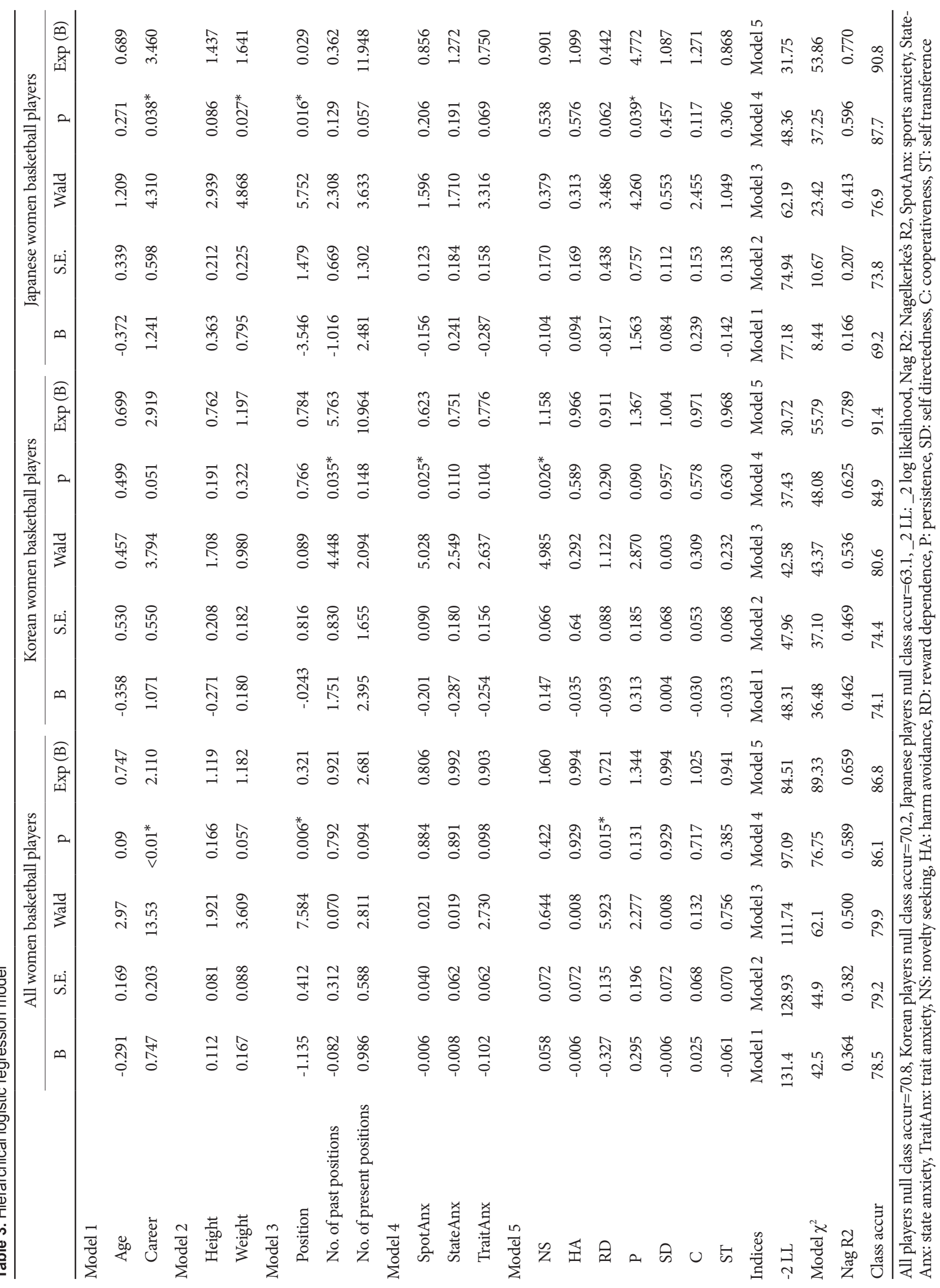


players. In TCI, NS was the most prominent factor for predicting national team players in WKBL players. In comparing pro-baseball starter and non-starter groups, NS was higher in the starter group than the non-starter group. ${ }^{10}$ Moreover, state anxiety was negatively correlated with NS scores. ${ }^{10}$ Regarding these results, higher NS traits would help control anxiety in becoming a Korean women national basketball player. Among WJBL players, those with lower anxiety could be national team players, which is not a surprising fact. We have described the relationship between lower anxiety and good performance above.

\section{Limitations}

There were several limitations in the current study. First, because the subjects were only women pro-basketball players, the results could not be generalized to all Korean and Japanese basketball players. Moreover, the design of the current study used a cross-sectional survey. Second, we did not assess performance skills and injury history in basketball players. The players' performance skills and injury history can affect their personality and anxiety. Future studies should include men and high school students in a longitudinal study design including scales rating performance skills and injury history.

\section{Conclusions}

To the best of our knowledge, this is first study to show differences in psychological characteristics between WKBL and WJBL players. The current study suggested that WKBL players showed higher anxiety and HA, and lower SD and cooperativeness, than the WJBL players. For predicting national team players, temperament and characteristics were crucial factors in WKBL players, whereas anxiety was the most important factor in WJBL players.

\section{Conflicts of Interest}

The authors have no potential conflicts of interest to disclose.

\section{Author Contributions}

Conceptualization: Doug Hyun Han. Data curation: Eun Joo Ha. Formal analysis: Doug Hyun Han. Funding acquistion: Doug Hyun Han. Investigation: Kyoung Doo Kang. Methodology: Doug Hyun Han. Project administration: Kyouung Doo Kang. Resource: Eun Joo Ha. Software: Eun Joo Ha, Kyoung Doo Kang, Doug Hyun Han. Supervision: Doug Hyun Han. Validation: Doug Hyun Han. Visualization: Eun Joo Ha. Writingoriginal draft: Doug Hyiun Han, Kyoung Doo Kang. Writing-review editing: Doug Hyun Han.

\section{ORCID iDs}

Doug Hyun Han https://orcid.org/0000-0002-8314-0767

Eun Joo Ha https://orcid.org/0000-0001-8121-1157

Kyoung Doo Kang https://orcid.org/0000-0003-4379-6435

\section{REFERENCES}

1. KBA. Koran Basketball Association. http://www.koreabasketball.or.kr. 2016. January 1, 2016.

2. JBA. Japan Basketball Association. http://www.japanbasketball.jp. 2016. January 1, 2016.

3. Boccia G, Moise P, Franceschi A, Trova F, Panero D, La Torre A, et al. Career performance trajectories in track and field jumping events from youth to senior success: the importance of learning and development. PLoS One 2017;12:e0170744.

4. Teramoto M, Cross CL, Rieger RH, Maak TG, Willick SE. Predictive validity of National Basketball Association Draft combine on future performance. J Strength Cond Res 2018;32:396-408.

5. Bayios IA, Bergeles NK, Apostolidis NG, Noutsos KS, Koskolou MD. Anthropometric, body composition and somatotype differences of Greek elite female basketball, volleyball and handball players. J Sports Med Phys Fitness 2006;46:271-280.

6. Dezman B, Trninic S, Dizdar D. Expert model of decision-making system for efficient orientation of basketball players to positions and roles in the game-empirical verification. Coll Antropol 2001;25:141-152.

7. Judge LW, Urbina LJ, Hoover DL, Craig BW, Judge LM, Leitzelar BM, et al. The impact of competitive trait anxiety on collegiate powerlifting performance. J Strength Cond Res 2016;30:2399-2405.

8. Otten M. Choking vs. clutch performance: a study of sport performance under pressure. J Sport Exerc Psychol 2009;31:583-601.

9. Arruda AFS, Aoki MS, Paludo AC, Moreira A. Salivary steroid response and competitive anxiety in elite basketball players: effect of opponent level. Physiol Behav 2017;177:291-296.

10. Kang KD, Han DH, Hannon JC, Hall MS, Choi JW. Temperamental predictive factors for success in Korean professional baseball players. Psychiatry Investig 2015; 12: 459-465.

11. Han DH, Kim JH, Lee YS, Bae SJ, Bae SJ, Kim HJ. Influence of temperament and anxiety on athletic performance. J Sports Sci Med 2006;5: 381-389.

12. Hoyt AL, Rhodes RE, Hausenblas HA, Giacobbi JPR. Integrating fivefactor model facet-level traits with the theory of planned behavior and exercise. Psychol Sport Exerc 2009;10:565-572.

13. Allport GW. The open system in personality theory. J Abnorm Soc Psychol 1960;61:301-310.

14. Hampson SE, Goldberg LR. A first large cohort study of personality trait stability over the 40 years between elementary school and midlife. J Pers Soc Psychol 2006;91:763-779.

15. La Place JP. Personality and its relationship to success in professional baseball. Research quarterly. Am Assoc Health Physic Educ Recreat 1954;25:313-319.

16. Cloninger CR. A systematic method for clinical description and classification of personality variants. A proposal. Arch Gen Psychiatry 1987; 44:573-588.

17. Cloninger CR, Svrakic DM, Przybeck TR. A psychobiological model of temperament and character. Arch Gen Psychiatry 1993;50:975-990.

18. Rettew DC, Stanger C, McKee L, Doyle A, Hudziak JJ. Interactions between child and parent temperament and child behavior problems. Compr Psychiatry 2006;47:412-420.

19. Cloninger CR, Przybeck TR, Svrakic DM. The Tridimensional Personality Questionnaire: U.S. normative data. Psychol Rep 1991;69:1047-1057.

20. Cloninger CR, Zohar AH. Personality and the perception of health and happiness. J Affect Disord 2011;128:24-32.

21. Cho SC. Assessment of Test Anxiety. Journal of Korean Neuropsychiatry 1989;28:668-677.

22. Hishinuma ES, Miyamoto RH, Nishimura ST, Nahulu LB, Andrade NN, Makini GK Jr, et al. Psychometric properties of the state-trait anxiety inventory for Asian/Pacific-islander adolescents. Assessment 2000;7:17-36.

23. Kim YS, Jang DS. The relationship between sport trait anxiety and the anxiety gene. J Coach Devel 2005;7:191-203. 
24. Sung SM, Kim JH, Yang E, Abrams KY, Lyoo IK. Reliability and validity of the Korean version of the temperament and character inventory. Compr Psychiatry 2002;43:235-243.

25. Kijima N, Tanaka E, Suzuki N, Higuchi H, Kitamura T. Reliability and validity of the Japanese version of the Temperament and Character Inventory. Psychol Rep 2000;86:1050-1058.

26. Knaster P, Estlander AM, Karlsson H, Kaprio, J Kalso E. Temperament traits and chronic pain: the association of harm avoidance and painrelated anxiety. PLoS One 2012;7:e45672.

27. Mellalieu SD, Hanton S, Fletcher D. A Competitive Anxiety Review: Recent Directions in Sport Psychology Research. Swansea city: Nova Science Publishers; 2006.

28. Halvari H, Gjesme T. Trait and state anxiety before and after competitive performance. Percept Mot Skills 1995;81:1059-1074.

29. Hajcak G, McDonald N, Simons RF. Anxiety and error-related brain activity. Biol Psychol 2003;64:77-90.

30. Wilson MR, Vine SJ, Wood G. The influence of anxiety on visual attentional control in basketball free throw shooting. J Sport Exerc Psy- chol 2009;31:152-168

31. FIBA. International Basketball Federation. https://en2019fbwc.damai. cn. Accessed July 23, 2017.

32. Hodge K, Lonsdale C, Jackson SA. Athlete engagement in elite sport: An exploratory investigation of antecedents and consequences. Sport Psychol 2009;23:186-202.

33. Stefani ED, De Marco D, Gentilucci M. Factors affecting athletes' motor behavior after the observation of scenes of cooperation and competition in competitive sport: the effect of sport attitude. Front Psychol 2015;6:1648.

34. Willer R, Sharkey A, Frey S. Reciprocity on the hardwood: passing patterns among professional basketball players. PLoS One 2012;7:e 49807.

35. Ortega E, Palao JM, Gomez MA, Lorenzo A, Cardenas D. Analysis of the efficacy of possessions in boys' 16 -and-under basketball teams: differences between winning and losing teams. Percept Mot Skills 2007; 104:961-964. 